\title{
THE EXCLUSIVELY RENEWABLE ENERGY POLICY AND STRUCTURE OF AN EXCLUSIVELY RENEWABLE ENERGY MARKET
}

Abstract: This paper considers the concepts of an exclusively renewable energy market on the basis of a hypothesis that the end of the fossil energy era is imminent and the advent of the exclusively renewable energy market is inevitable. It examines energy policies and their suitability for transition to an exclusively renewable energy market as well as drawing on some possibilities for integrating renewable energy policies into current mainstream energy policies. The major part of the paper is devoted to the study of an exclusively renewable energy market structure which would consist almost exclusively of renewable electricity and not biofuels. The qualities of various renewable energy sources are considered and evaluated in order to determine they part in future exclusively renewable energy market. Individual or end-consumer renewable electricity production is considered to be the dominant trend in an exclusively renewable energy market.

Keywords: energy, economy, renewable energy policy, renewable energy market, energy market structure, individual energy production, end-consumer, electricity, biofuel, fossil fuels

T oday it seems obvious to academics, the general public, and governments that the fossil energy era is almost over. At the very least, we are sure that it will be over one day. As a consequence, we are on the verge of the era of renewable energy. Therefore, it is interesting to study how governments are reacting to this major shift, and adapting not only their energy policies but policies in other economically significant sectors also.

Although it is now possible to discuss significant changes in government energy policies, it seems that these changes are mostly driven by the need to adapt energy policy to climate change objectives or to energy security and energy availability objectives. In other words, it seems that changes to energy policy are mostly driven by humanistic values (e.g. environmental protection) or by the scarcity of energy resources and rising energy prices as opposed to the need to switch to a renewable energy economy.

Thus, it is interesting to imagine not only how the switch from fossil fuels to renewables will take place and how this change will be influenced by government policies, but also to envisage how an exclusively renewable energy market will operate once fossil fuels disappear altogether.

The current state of the energy market is irreversible: fossil fuels have become expensive not only because of growing demand from emerging economies but also because their extraction has become more costly. This means that alternative energy policies are now economically viable, and governments need to seize this opportunity as soon as possible in order to guarantee their dominant position in an exclusively renewable energy world and to make their economies more competitive in the global market.

\section{Exclusively renewable energy policy}

\subsection{The realities of contemporary energy policies}

The globalized world economy is characterized by extremely high concurrence of different markets; relations and tensions between the actors of the different markets are no longer (or no longer exclusively) based on a national or a regional scale but on a global one. As a consequence, national governments are more preoccupied by their economies' security, resilience, and competitiveness globally. This explains why protectionism is considered as a normal trend of every government economic policy today, and not just a corollary of the "hard times" of the current economic crisis.

The same trends can be observed in energy policy. While the proportion of developed countries' global demand for energy is shrinking, in terms of volume it is still increasing; at the same time, the demand for energy in developing countries is constantly rising. The combination of these features makes the energy market highly competitive. As a consequence, government energy policies are focused more on energy security than oft-used humanistic reasons such as environmental protection and the reduction of $\mathrm{CO}_{2}$ 
emissions. Evidence for this assumption can be found in the resurgence of US oil and gas production as well in European policies in relation to the diversification of energy suppliers. In other terms, current government energy policies are fixated on securing the supply of and a reasonable price for energy resources rather than on climate change objectives, which clearly take a secondary role.

Indeed, contrary to what is often stated, the development of renewable energy policies is mostly due to the rising prices of fossil fuels and to technical advances that have brought about the production of cheaper renewable energy. Specifically, clear policies dealing with renewable energy have become accepted because of high fossil fuel prices and the understanding of the finite nature of fossil fuels. The depletion of fossil fuels and its concomitant consequences - an increase in the price of their extraction and production as well as a decrease in their supply - will not affect high energy prices even if new extraction technologies are implemented or if new fossil energy resources (whether conventional and unconventional) are discovered. In other terms, the constantly growing demand for energy, which has not faltered even during the economic crisis, and the depletion of fossil fuels as an energy source will continue to support high prices of energy sources, prices that are now similar to the prices of renewable energy production. This fact gives rise to governments being able to implement "green energy" policies and means that government energy/ environment policies are motivated not only by the desire to meet climate change objectives but by national energy/ economic security factors.

This view of contemporary energy policies changes the conventional view of the development of renewable energy sources. Traditionally, the development of renewable energy sources was considered to be an environmental aspect of energy policy, required to meet environmental objectives, whereas nowadays it is part of energy security and economic policies. Energy-efficiency measures taken by governments can be considered in a similar manner: they are used to create a more competitive economy which will hopefully survive in a globalized market rather than to reduce $\mathrm{CO}_{2}$ emissions or promote other climate change objectives. Indeed, while energy-efficiency policies are aimed at reducing energy consumption and the demands for energy, they are not aimed at decreasing the consumption of the most polluting energy sources. Government measures that tend to cut demand for energy (or to implement energyefficiency measures) are not supposed to reduce negative environmental effects. Nevertheless, the fact that these measures are not supposed to harm or to affect in any negative way the economic growth of the country (as the least harmful solution) gives rise to the argument that these kinds of measures tend to improve the global competitiveness of economies that implement such measures.

The same can be said about energy security measures, especially measures that have been taken by energy-importing countries. Such measures tend to reduce the energy dependence of importer countries or tend to undermine the energy supplier countries' dominant position on the energy market via the diversification of the energy suppliers. European countries, for example, have taken such measures to undermine the dominant position of Russia in European natural gas markets. Other energy importer countries have used or are trying to implement similar energy security measures, measures which are especially designed to increase internal energy production in order to reduce dependence on energy imports. The United States have recently changed their energy policy in order to reduce their dependence on energy imports. Such measures are justified and must be taken by importer countries because of high energy prices and as a consequence of the fact that energy plays a more important role in all economy sectors than before. This sort of "energy protectionism", which tends to regionalize or nationalize energy markets, is illusive because global market fluctuations will nevertheless impact on internal energy markets. Moreover, the way in which "energy protectionism" is realized in the US - through an increase in the production of unconventional fossil fuels - is completely wrong because this policy is directed towards finite energy sources and should be considered only as a mid-term energy policy.

Finally, it is worth mentioning that these conclusions about current government energy policies are underpinned by the International Energy Agency assumption that "Successive editions of (...) report have shown that the climate goal of limiting warming to $2^{\circ} \mathrm{C}$ is becoming more difficult and more costly with each year that passes"'. In other terms, governments do not implement climate change objectives if they are seen to be economically counterproductive. Moreover, the most polluting economies of tomorrow are the larger emerging or developing countries (China, India, Russia), all of which lack strong humanistic values, such as environmental protection. It would be difficult to convince the governments of these nations to take climate change objectives on board since their citizens do not hold such values and would not influence their governments to devise energy policies with a greater focus on environmental protection. The difference between the energy policies of emerging and developed countries is based on the way in

\footnotetext{
${ }^{1}$ See World Energy Outlook 2012.
} 
DOI: $10.7256 / 1811-9018.2013 .11 .10034$

При цитировании этой статьи сноска на dоі обязательна

\section{Право и политика $11(166) \cdot 2013$}

which they are presented to their citizens: developed countries put forward energy security measures in the guise of environmental policy objectives because these are seen to be more appealing to their populations, while developing economies willfully ignore environmental objectives in their energy policies because of the economically harmful character of such objectives.

It would be absurd, however, to conclude that government energy policies are completely devoid of environmental protection objectives. Such elements are particularly evident in the energy policies of European countries, in which public opinion and political actors are more likely to promote humanistic (and especially environmental) values. Nevertheless, while environmental values are intensively integrated into all government policies in Europe, it seems that such policies are not welcomed by all Europeans (and especially by economic actors). The main reason for the lack of support of intensive integration of environmental values into the energy policies of developed countries (in Europe and in other Western countries such as the USA) is the fact that such values are not integrated into the energy policies of developing countries. Developing countries do not have a strong tradition of humanistic values and their public opinion is not yet powerful enough to force their governments to take action in order to protect the environment. Therefore, the causes of the problems of intensively integrating environmental values into the energy policies in developed countries are found in the different approaches to energy policy of developed and developing countries. This is perfectly understandable: the integration of such values by a small number of members of the international community would harm the competitiveness of their economies in globally dependent markets, since any environmental action has economic costs (given the fact that such actions are not driven by profitability). In other terms, full incorporation of such values in energy policy would be self-destructive for the competitiveness in global markets of the economies of countries which take such steps.

\subsection{Energy policies of the future}

The overview of government energy policies makes it clear that environmental protection is not their priority. It seems that climate change is not considered to be a serious problem for humanity and as an issue which could cause our demise. This is true not only in relation to government positions but is also the dominant public opinion. Consider the idea that the environmentally harmful effects arising out of energy use are due to the use of fossil fuels and that such effects will disappear in an exclusively renewable energy market ${ }^{2}$. Indeed, given the fact that fossil fuel stocks will be depleted in only a few decades' time and that even unconventional fossil fuels will not provide a suitable long-term replacement, the sources of the environmentally harmful effects will cease to exist well before the effects of any environmental policy can play a major role in the reduction of $\mathrm{CO}_{2}$ emissions. In other words, any current energy policy which is premised upon energy security must be refocused to the most important goal - to provide a smooth transition to an exclusively renewable energy market and not to the problems that will solve themselves regardless.

The argument that energy policy must be driven by the objective of the transition to a renewable energy policy and not merely clean energy has to be validated. Not all sources of renewable energy are environmentally friendly. Indeed, biomass is a notable exception - it is a renewable energy source that has negative environmental effects comparable to fossil fuels. Nonetheless, renewable energy sources are mostly environmentally friendly (or are at least more environmentally friendly than fossil fuels). Therefore, environmentally friendly energy policies can be implemented even if they do not pursue this objective directly. The inevitable end of the fossil fuel era and its replacement by renewable energy sources will, of necessity, bring us to a reduction in $\mathrm{CO}_{2}$ emissions and to the implementation of environmentally friendly policies. In other words, the manifest and core objective of new energy policies must be the switch from fossil fuelcentered policies to renewable fuel policies and not merely to environmentally friendly energy policies, because this choice will lead not only to the implementation of environmentally friendly policies but is also the strategically correct choice.

In spite of the environmentally friendly character of renewables, "dirty" renewables such as biomass can play only a secondary role in future energy policies and so will not have a major environmental impact. Indeed, given the fact that global energy demand will rise, future energy policies could not be based on renewable energy sources that would satisfy only a small part of the energy demand of the global society of the future. In other terms, the growing energy needs of the global population could not even partly be satisfied by this renewable source of energy because of the small potential for growth in the biomass market and its concurrence with non-energy-sector use of the raw materials (primary energy sources) of biomass in an exclusively renewable world ${ }^{3}$.

\footnotetext{
2 The only "dirty" renewable energy source is biomass, but as we will see below (paragraph 2) this energy source could not dominate (or even play any significant role in) an exclusively renewable energy market. ${ }^{3}$ See more below, paragraph 2.
} 
The development of another renewable source of energy - hydropower - can be undertaken only if particular conditions exist. Indeed, hydropower projects can be useful in future energy policies only under certain conditions because they are controversial when it comes to the environment. Originally, they were considered positively by the public because of their zero- $\mathrm{CO}_{2}$-emissions energy (electricity) production process. Nonetheless, the high environmental cost of flooded areas and the subsequent pressure from a concerned public led some Western governments to abandon the idea of developing more hydropower projects. Future energy policies must reintegrate this source of renewable energy by slightly changing the use of hydropower. The solution to the environmental problems caused by large-scale flooding for hydropower is the use of medium-sized and small hydropower plants. The development of energy production technology for individualized energy production ${ }^{4}$, which woud take the form of small energy production units being used on a large scale, allows for the integration of hydropower.

Other sources of renewable energy, such as solar, wind, water (tidal and hydro) and geothermal energy sources, undoubtedly have a future in every energy policy scenario (the environmentally-friendly-centered energy policy; the transition-to-renewables-centered energy policy; and even the fossil-fuel-centered energy policy) and are not seen as controversial by the public. Further examination of the place of renewable energy sources in the exclusively renewable energy market of the future appears below ${ }^{5}$. At this stage, it is sufficient to consider two examples of current energy policy that are not consistent with the transition to an exclusively renewable energy market, and which testify to the fact that such a policy is unfortunately not integrated into current government energy policy.

The first example is that of nuclear energy. Until recently, there was a popular view that nuclear energy was renewable because it is a relatively clean energy source: nuclear energy produces low amounts of $\mathrm{CO}_{2}$ emissions in the process of electricity generation ${ }^{6}$. Nevertheless, notwithstanding the "almost clean" (and, by today's energy prices, even cheap) characteristic of nuclear power, this source of energy cannot be integrated into Western government policies as such, and not only because of its now "bad" reputation in the eyes of the public (especially since the Fukushima Nuclear Plant accident). Given the fact

\footnotetext{
${ }^{4}$ See paragraph 2 below.

${ }^{5}$ See paragraph 2 below.

${ }^{6}$ See, for example, World Energy Outlook 2010.
}

that the raw materials for this source of energy are finite (as any fossil fuel), we cannot rely on them over the (very) long term. In other words, this source of energy cannot be integrated into an exclusively renewable energy market even if nuclear energy appears very attractive as part of today's popular climate change-centered energy policies (at least for developing countries).

The development of unconventional fossil fuels is another example of recent energy policy changes that can be criticized in light of the advent of an exclusively renewable energy policy. Their development can be criticized not only because of their environmentally harmful effects, but more importantly, for the lack of logic in the decision to focus on finite energy sources at the end of the fossil fuel era. Indeed, the fact that unconventional fossil fuel stocks are finite means that this policy choice is mid-term one. Moreover, it is not economically viable: this policy only hinders the inevitable transition to an exclusively renewable energy world and will cause the economies that make such a decision to become fragile compared to the economies that choose renewable energy policies. Indeed, policies focused on unconventional fossil fuels delay the necessary overhaul of all sectors of the economy (from transport to industry and the private sector), which would be necessary due to the inevitable transition from a fossil fuel-centered economy to a renewable energy economy. An unconventional fossil fuels energy policy is strategically unreasonable and jeopardizes the competitiveness of national economies that make such a choice on a global level.

The criticism of recent energy policy above makes sense because renewable energy policies can be implemented today. This can be gleaned from the fact that fossil fuel prices will never really be lower than they are now, and will only increase in the long term. The key reasons for this trend are the ever-increasing demand for energy as well as the growing costs of extracting the remaining fossil fuels. Indeed, given the fact that all the easily-extractable fossil energy sources have already been extracted and consumed, the cost of the remaining fossil fuels can only increase, ensuring the middle- and long-term economic viability of projects for renewable energy sources.

\section{The structure of an exclusively renewable energy market}

This section presents a long term and a very long term forecast of the outcomes of the end of the fossil fuel era and the nature of an exclusively renewable energy policy: a global energy market without fossil fuels. It will discuss the shares held by various fuels (biofuels), biomass, and 
DOI: $10.7256 / 1811-9018.2013 .11 .10034$

При цитировании этой статьи сноска на doi обязательна

\section{Право и политика $11(166) \cdot 2013$}

renewably produced electricity in the energy market of the future. In other terms, it will present the possible structure of the renewable energy market by exploring the physical characteristics of renewables as well as the appeal and economic viability of renewables. How will these characteristics determine the place of each renewable energy source in the energy market of the future?

\subsection{The characteristics of renewables and their place} in the energy market

The most popular or fastest-growing renewable sources of energy today are biomass, biofuels, and electricity produced from different renewable sources of energy (wind, solar, water). Renewable sources of energy are used in the same forms as conventional sources of energy: as fuels (liquid or solid) or as electricity (immaterial). Moreover, contemporary renewables have been conceived and produced using conventional energy sources as a model in order to easily replace them, and they can be categorized as such. Conventional sources of energy can be divided into two major categories: primary energy sources (biofuels, which are mostly produced from plants and are used for transportation, and biomass for heating) and secondary energy sources (electricity). The first category is mostly used in the transport sector. These energy sources can be used in the non-energy sector (fuels) or for heating houses (biomass) and are characterized as highenergy density products, mostly as liquid or solid forms. The second category is produced on a secondary basis via transformation of energy sources into electricity: wind, solar and water resources are used in the same way that coal, gas, and nuclear fuels produce electricity.

In other words, the uses of renewable energy sources mimic the forms and types of use of conventional energy sources. Thus, biofuels (e.g. bioethanol) were created to replace the ubiquitous petroleum in the transportation sector, whereas immaterial sources of energy (wind, solar) are, by their nature, used exclusively to produce electricity. Biofuels were recently developed because electricity cannot completely replace petroleum in the transportation sector: biofuels take a material form while electricity cannot be produced or reproduced as a liquid or a gas form of energy, forms which have high energy density. Due to their physical characteristics, biofuels have already made inroads in the transportation sector by replacing petroleum; they are similar to fossil fuels and their versatility allows them to be used without a complete overhaul of the transportation industry.

In the future, biofuels could take the leading role in an exclusively renewable energy market, in the same way that fossil fuels (oil and gas) dominate the market today. This is because the major consumers of this type of fuel are in the transport sector and because of the versatility of biofuels. Despite such similarities between the uses of conventional and renewable fuels, the renewable energy market will be very different from today's energy market. Indeed, while petroleum and other liquid/solid forms of energy sources play major roles in today's predominantly fossil-fuel energy market, the focus of an exclusively renewable energy world will be electricity and not biofuels, which are replacing the dominant energy source currently. This assumption leads to the conclusion that in the future, all sectors of the economy will undergo a complete overhaul because of the impossibility of the use of material energy sources (liquid and solid forms of energy).

Nonetheless, in comparison to electricity, biofuels (and biomass) have great advantages: they can be stocked en masse; they have a high energy (power) density, which is why they are most suitable for the transportation sector; and they can produce other forms of energy (electricity). In other terms, they are extremely versatile and, therefore, very attractive energy sources for all sectors of massconsumption economies.

Indeed, the most unattractive characteristics of electricity derive from its immaterial character. It is impossible to stock huge quantities of this source of energy; electricity produced must be immediately consumed and can be stored only in small quantities. This is incompatible with mass consumption of huge quantities of energy in today's developed countries. The same immaterial characteristic of electricity forbids its transportation outside the electric power grid, which means that this type of energy cannot be transported over long distances, unlike fossil fuels. Moreover, the transmission and distribution of electricity via the grid results in energy losses (through heat and conductor resistance), despite being cheaper than the transportation of fossil fuels.

It seems unlikely that any technological advances will allow for the storage of the huge quantities of this type of energy which is necessary for large-scale consumption. Nor will there be transcontinental transmission of this type of energy, as it has always been complicated and results in losses of electricity during its transportation. At first glance, the immaterial characteristic of electricity makes this source of energy unattractive and partly explains the development of the biofuels industry.

If the (im)material qualities of electricity are so unattractive in comparison to fossil fuels, then it is paradoxical that the IEA and the OECD forecast that world electricity demand is expected to continue to grow more strongly 
than any other final form of energy? ${ }^{7}$ Interestingly, the existence of biofuels and biomass has not led to the abandonment of the concept of the electric car, which will no doubt replace internal combustion vehicles (even if they are powered by biofuels).

\subsection{Electricity as a major form of energy in the future}

Despite its unattractive qualities, electricity will dominate the energy market in the future because of:

1. The relative availability of the renewable primary resources used for electricity production and their free-ofcharge characteristics;

2. The non-interference of these primary resources with non-energy economy sectors; and

3. The possibility of electricity production on an individual, end-consumer level.

2.2.1. The main renewable primary sources of energy used for electricity production are solar, wind, water, and geothermal energy. While biomass and biofuels need primary sources (raw materials) such as wood or plants (e.g. sugar cane, corn, other vegetation) in order to be produced and to be reprocessed in order to create useable fuels, solar power, wind and water (and even geothermal energy) used exclusively for electricity production (or heat) are not restricted in terms of their availability and are cost-free. Indeed, the problem with biomass and biofuels is the availability of land necessary to grow the primary raw materials (wood and plants) and the necessity to (re)produce them. Moreover, even if energy from the sun, water, and wind is not dispersed equally in the world, it is not need human intervention to be reproduced. The availability of this sort of energy does not depend on seasonal grounds (seasonal crop growth) nor does this energy take any time to grow. All in all, although biomass and biofuels are renewable sources of energy, the need for human intervention in the process of their reproduction (agriculture and forestry) make them

\footnotetext{
${ }^{7}$ World Energy Outlook 2010, p. 50. The assumption of the IEA experts that demand for electricity will grow only in developing countries is incorrect. It is more likely that electricity demand will be stronger than they foresee and be driven by both developing and Western nations. Electricity demand in developed countries will grow strongly because of the abandonment by Western countries of nuclear energy (under pressure from the general public; people have been mistrustful about this source of energy for many years and have become even more so after Fukushima Nuclear Plant accident). This would reduce the supply of electricity. Further, there will also be stronger demand in the transport sector: cost pressures due to the price of fossil fuels used by vehicles will force the sector to switch to renewables, and especially to electricity (and not to biofuels) as the most attractive source of energy (see details in paragraph 2 below).
}

less economically attractive in comparison with other primary sources of renewable energy (solar, wind, water and geothermal). Quite simply, primary sources of renewable energy for biomass and biofuels presuppose some costs because they need be produced (planted, grown or at least harvested, in the case of wood). On the other hand, human intervention is not needed for the renewable primary sources of electricity production: solar, wind, water and geothermal (re)production is free.

There is no need for further analysis of the differences between the nature of the primary sources for biofuels/ biomass and the nature of renewable primary sources of electricity because of the economically attractive character of the latter. From this perspective, even new technologies that have made it possible to grow some raw materials for biofuels in water (algae) and therefore avoid the need for a resource as scarce as land, cannot change the destiny of the energy market of the future in the face of the following argument.

2.2.2. The non-interference of electricity production from above-mentioned renewable sources with non-energy economy sectors can be easily explained. But in order to prove that renewable electricity is more attractive than biofuels/biomass, and to demonstrate that the energy market of the future will almost exclusively belong to electricity, it is necessary to explain the theory that in a world without fossil fuels, biomass/biofuels would interfere with non-energy sectors of economy and impede them. In the absence of fossil fuels, their place in the non-energy sectors of the economy will have to be taken by something else. The alternatives will be those products that can potentially be used as primary sources (raw materials) for biofuels/biomass. Indeed, given the fact that fossil fuels today are used not only as an energy source but also as lubricants, as ingredients in medicine, and as various other industrial components, it is likely that these forms of demand for fossil fuels will be in future replenished only by biofuels/biomass raw materials. In other terms, the development of biofuels (and even of biomass) for the energy sector will be counterproductive as it will deprive our industries and other economic sectors of valuable raw materials.

Almost one-sixth of petroleum consumption today takes place in the non-energy sectors: manufacturing goods (plastics), construction (asphalt production), pharmaceuticals (medicines), and agriculture (fertilizers and pesticides). In other words, there are many non-energy uses of petroleum and other fossil fuels (e.g. coal is used to make steel, carbon fibers and some polymers). Since non-renewable fossil fuels are finite and will eventually be used up completely, the 


\section{Право и политика $11(166) \cdot 2013$}

source of most of our manufactured goods, products and raw materials will also dry up, and we will have to find a renewable solution to replace them. Even if waste products were to replace fossil fuels in non-energy sectors (by means of recycling), the only reliable solution to replacing fossil fuels in non-energy sectors will be found in renewable primary sources such as wood, plants, and algae.

Because of the growing demand for energy and raw materials, the only viable source of material primary sources in the future will have to be renewable; that is why waste recycling is only part of the solution. We will not be able to use raw materials for biomass and biofuels in the same way that we have been using fossil energy resources in the energy and non-energy sectors (such as the petroleum we have been using for several decades). The problem of biofuels/biomass lies not only in the fact that their primary sources have to be produced and reproduced, generating human intervention and therefore attracting costs (as opposed to the simple harvesting or extraction of fossil fuels); other uses of the raw materials for biofuels/biomass, such as wood and plants, will compete with other non-energy sectors of the economy, e.g. agriculture (for plants) and construction (for wood). Likewise, the production and use of renewable biofuels such as cellulosic fuel will deprive the construction sector, as well as other sectors of the economy, of necessary materials. Similar issues apply to the development of biomass.

The problem lies in the fact that rising demand for raw materials for the energy sector as well as for non-energy sectors will not be satisfied in the post-fossil-fuel world by wood or plants alone. This is due to the scarcity of the land which is needed to grow these raw materials. In other terms, in an exclusively renewable energy market, biofuels/ biomass would be not only less profitable energy sources than renewable electricity, but they would also hamper the development of non-energy economy sectors, because such renewables would directly compete with them in the market for raw materials. In contrast, renewable electricity uses primary sources that have an immaterial character (sun, wind, water) and therefore cannot be used in the non-energy sectors of economy.

2.2.3. One of the key issues that will impede the development of the biofuels energy market in the future is the impossibility of their production on an individual (endconsumer) level.

Technological development has an impact on energy production and consumption. Today's technology already allows us to create small renewable energy production units that can produce economically viable energy (e.g. photovol- taic panels). Moreover, given the advances in technology and the rise of energy prices due to the depletion of cheap fossil fuels, which today are more expensive to extract and will never be as cheap as before, this trend will likely only continue into the future. In other terms, we are on the verge of the era of economically viable individual production of renewable energy (electricity). Will it impact upon other sources of renewable energy (biomass and biofuels)? Not at all, since the only renewable energy that can be produced on an individual level is electricity.

Today, the small units of individual energy production that dominate the individual renewable energy production market are mostly solar (photovoltaic) panels and small-scale wind turbines. Hence, the current market for individual energy production is limited to electricity production, and this situation is not likely to change in the future. The reason for this lies in the peculiarities and differences between biofuel production and renewable electricity production. Unlike biofuels, electricity does not require an industrial production process and can be created by individuals with the help of small energy production units. Even if the agricultural/ forestry processes - planting, caring for, harvesting - needed to produce the raw material for biomass/biofuels are overlooked, their production involves complicated processing such as distillation and purification. All in all, biofuels cannot be produced on an individual level. The use of biomass on an individual level is mostly limited to heating, and it cannot produce (at least on an individual level) electricity or fuel that can be used for transportation or other sectors.

It is clear that electricity is the only energy form that can be produced on an individual level. So why is individual energy production so important? Will it dominate the future energy market?

This kind of energy production/consumption has several advantages. First of all, it is very attractive because it is produced where it is consumed: by the end-consumers. It excludes (or at least diminishes ${ }^{8}$ ) transportation/transmission costs and, more importantly, it ameliorates one of the unattractive characters of electricity - its problematic transmission and distribution - by reducing or eliminating transmission and distribution losses.

Secondly, the development of individual energy production results in a reduction of the problems inherent in large-scale energy projects. Indeed, even renewable energy production on a large scale brings some public discontent,

\footnotetext{
${ }^{8}$ Electricity consumed on an individual level will never be supplied wholly by its "production on the premises". The grid will always be necessary in order to transmit the electricity from the producer to the consumer or - more precisely - to exchange the electricity between the producers-consumers.
} 
e.g. the industrialization of landscapes due to the installation of the industrial wind turbines, and the flooding of areas caused by hydropower dams. Even if small energy production units, such as solar panels and domestic wind turbines, are sometimes contentious, individual energy production moves the burden of the responsibility for energy production from the government level to the individual level. This effectively removes the responsibility for politically delicate energy policy decisions (large-scale energy projects) from governments. Moreover, in Western mass economies, where the demand for energy is mostly determined by individual domestic consumers 9 , individual energy production could satisfy the major proportion of this demand and therefore reduce the necessity for large-scale energy projects. Furthermore, the possibility for consumers to produce energy on their own, coupled with high energy prices, will stimulate them to produce as much energy as possible in order to satisfy their needs and to avoid buying expensive energy from others. At the very least, given the fact that the number of large-scale renewable energy projects is limited due to reasons such as negative public opinion and physical reasons (the availability of large quantities of land), then individual energy production seems to be the only proposition for the energy market of the future.

Finally, small-scale renewable energy projects are inherently eco-friendly. Although hydropower projects produce renewable energy and are "clean" from a zero- $\mathrm{CO}_{2}$-emissions perspective, large-scale hydropower energy projects can be subject to public opposition. Despite the renewable character of hydropower and its indisputable place in future energy policies, its poor reputation, which has come about because of the negative effects of devastating flooding on sometimes important ecosystems, has to be dealt with. Whereas solar panels and wind turbines have already proven their viability in terms of individual energy production, small-scale hydropower projects have not yet been developed, essentially for technical reasons, even though they could be in the future, giving the fact that such small hydropower energy projects are by nature eco-friendly.

In the future, we will all be part of the development of a huge market for individual energy production units that will be comparable to the recent development of the market for personal computers. This market will be occupied exclusively by electricity production units. The fact that individual energy production will touch upon electricity production only will reduce the scope of energy markets to the local and the regional scale. It appears absurd that one aspect of a globalized economy - that is, the energy market - could be determined locally or regionally, but the immanent characteristics of electricity makes it clear that energy markets will be more locally dependent than globally dependent. On the whole, the switch from the fossil fuel-dominated market to a renewable energy market, dominated by electricity, will scale back the energy market from a globally structured market to a locally or a regionally structured one.

\section{Библиография:}

1. IEA, World Energy Outlook, 2010

2. IEA, World Energy Outlook, 2012

3. J.P. Tomain, R. Cudahy, Energy Law, West, 2012

\section{References (transliteration):}

1. J.P. Tomain, R. Cudahy, Energy Law, West, 2012

\footnotetext{
${ }^{9}$ For example, more than half of US energy demand originates from the transportation, commercial and residential sectors, and is mostly due to individual energy consumption. See USDOE, Annual Energy Report (2006), for example.
} 